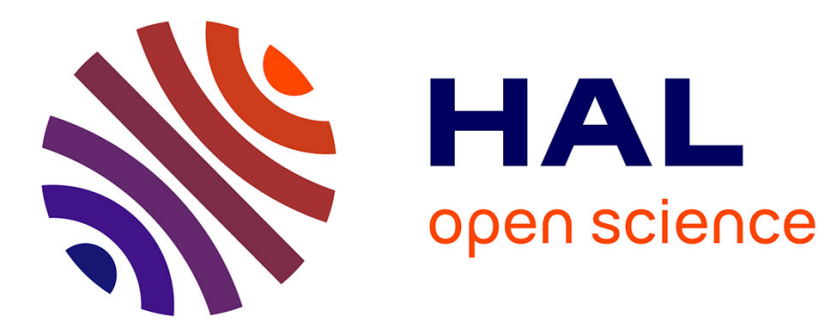

\title{
Environmental and Economic Assessment of a Greenhouse Waste Heat Exchange
}

\author{
R. Andrews, J.M. Pearce
}

\section{To cite this version:}

R. Andrews, J.M. Pearce. Environmental and Economic Assessment of a Greenhouse Waste Heat Exchange. Journal of Cleaner Production, 2011, 19 (13), pp.1446-1454. 10.1016/j.jclepro.2011.04.016 . hal-02120486

\section{HAL Id: hal-02120486 \\ https://hal.science/hal-02120486}

Submitted on 6 May 2019

HAL is a multi-disciplinary open access archive for the deposit and dissemination of scientific research documents, whether they are published or not. The documents may come from teaching and research institutions in France or abroad, or from public or private research centers.
L'archive ouverte pluridisciplinaire HAL, est destinée au dépôt et à la diffusion de documents scientifiques de niveau recherche, publiés ou non, émanant des établissements d'enseignement et de recherche français ou étrangers, des laboratoires publics ou privés. 
Published: R. Andrews and J.M. Pearce, "Environmental and Economic Assessment of a Greenhouse Waste Heat Exchange”, Journal of Cleaner Production 19, pp. 1446-1454 (2011). http://dx.doi.org/10.1016/j.jclepro.2011.04.016

\title{
Environmental and Economic Assessment of a Greenhouse Waste Heat Exchange
}

\author{
R. Andrews a, J. M. Pearce* ${ }_{a}$ \\ a Department of Mechanical and Materials Engineering \\ Queen's University \\ 60 Union St. \\ Kingston, $\mathrm{ON}$ \\ K7L 3N6
}

Contact:

J. M. Pearce

Phone: (613) 533-5569

Fax: (613) 533-6489

pearce@me.queensu.ca

Department of Mechanical and Materials Engineering

Queen's University

60 Union St.

Kingston, $\mathrm{ON}$

K7L 3N6

\begin{abstract}
:
As the economic costs of energy and the negative externalities associated with the combustion of fossil fuels threaten the economic viability of greenhouses in northern climates there is a renewed interest in the use of waste heat. This paper presents a technical and economic methodology to determine the viability of establishing waste heat greenhouses using the waste heat from industrial processes in northern climates. A case study is presented of an exchange between a tomato greenhouse and a flat glass manufacturing plant, which found the waste heat system is significantly more economic to operate than a purely natural gas system.
\end{abstract}

Keywords: industrial symbiosis; waste heat; exchange; greenhouse; industrial ecology; by-product exchange 
Published: R. Andrews and J.M. Pearce, "Environmental and Economic Assessment of a Greenhouse Waste Heat Exchange”, Journal of Cleaner Production 19, pp. 1446-1454 (2011). http://dx.doi.org/10.1016/j.jclepro.2011.04.016

\section{Introduction}

The intensifying global focus on environmental responsibility has forced industries and policy makers to develop strategies to mitigate and avoid the production of harmful emissions, while maintaining economic viability in the marketplace (Stern and Treasury, 2007; IPCC, 2008). To this end, recent work has even called for energy policy to be focused on real energy economics based on life-cycle carbon emissions (Kenny, et al., 2010). Although this focus has lead to an increase in the adoption and adaption of renewable energy technologies (Sims, 2004), the least expensive energy is the energy that never has to be produced in the first place (Lovins, 1996). To this end it has been shown that reducing the energy and carbon intensity of existing industrial processes, known as demand side management, will play a critical role in reducing global carbon concentrations (IPCC, 2007). This focus on demand side management has led to more stringent emissions controls on many industries coupled with incentive programs to improve overall system efficiencies, which force industry to critically analyze all facets of their energy usage. In Canada the energy efficiency index, a measure of energy used per unit production in the Canadian industrial sector, has been steadily increasing since its inception in 1990, reaching an increase of 13\% from 1990 levels in 2003 (OEE, 2006).

Additionally, the volatility of fuel prices has made the improvement of process efficiency not only a good environmental decision, but a sound business decision. Consumer natural gas prices have varied widely from \$2.48/GJ and a maximum of \$11.38/GJ from 2003 to 2010 (Gov. of Alberta, 2010). Companies who are able to more efficiently utilize energy will be better positioned to succeed during times of increased fuel costs. The efficient use of energy can take many forms; there are internal improvements which include steps such as improving the efficiency of electrical motors, the improved usage of compressed air and increased combustion efficiencies in boilers to name a few (Kreith and Goswami, 2007; Thumann, 1977; Wulfinghoff, 1999) and external improvements which can include the transfer of energy and materials streams with external companies using industrial symbiosis, which can make better use of these traditional "waste" products (Chertow, 2000). When implemented properly, these by-product exchanges can improve not only the environmental performance of a grouping of companies, but can also have significant economic advantages as well (Mirata, 2004).

This paper will provide a methodology to determine the technical and economic viability of using industrial waste heat effectively to heat greenhouses in northern climates. Waste heat recovery in the glass industry is not a new concept, and has been used in the past to provide process steam, space heating, and to improve cycle efficiency (Khinkis et al., 1968; Nycz and Sturgill, 1980; Richards, 1980; Hnat and Coles, 1985; OIT, 2002; Kobayashi et al., 2005). In addition, the energy modeling of greenhouses has been previously explored (Chalabi et al., 2002a; Chalabi et al., 2002b; Chau et al., 2009) and the prediction of yields and the economic values associated with them have been well studied (Nilsen et al., 1983 ; Chalabi et al., 2002a; Chalabi, 1992). However, the industrial symbiosis between the glass manufacturing process and greenhouse space heating has not yet been fully explored, from a technical and economic perspective and this is the goal of this paper.

Specifically, a case study will be presented of the combination of flat glass manufacturing with commercial greenhouses, for example to improve the efficiency of an eco-industrial park centered on

. CHP: Combined Heat and Power

ASABE: American Society of Agricultural and Biological Engineers

MARR: Marginal Acceptable Rate of Return 
Published: R. Andrews and J.M. Pearce, "Environmental and Economic Assessment of a Greenhouse Waste Heat Exchange”, Journal of Cleaner Production 19, pp. 1446-1454 (2011). http://dx.doi.org/10.1016/j.jclepro.2011.04.016

solar photovoltaic factory in need of substrate glass (Nosrat et al., 2009; Pearce, 2008). In this case study, the glass manufacturing industry was chosen as it has a large availability of flue gas heat. In addition, because fossil fuel powered glass plants burn natural gas, which produces carbon dioxide $\left(\mathrm{CO}_{2}\right)$ with relatively low sulfur dioxide and other pollutants (US EPA, 1995), correctly treated flue gasses could possibly be used for $\mathrm{CO}_{2}$ enrichment of greenhouse crops. Tomato greenhouses are investigated here because of their large market share in the Canadian greenhouse market (Statistics Canada, 2008), and the wide body of literature related to their growth requirements and optimization. It should be noted however, that the case study of these two specific industries is meant to provide an illustrative example of a possible system, while the same analysis demonstrated here is applicable to a wide range of industry and greenhouse combinations

\subsection{Waste Heat as a Commodity}

The term "waste heat" refers to heat that is either lost through the flue stack of an industrial operation, or which is rejected from a power generation station to improve the thermodynamic efficiency of the cycle. The temperature of this heat is necessarily lower than the combustion temperatures used for power or process steam generation of furnace operation, but are still generally at a high temperature with a large availability of exergy. The re-use of waste heat is well established and has been implemented successfully in several different contexts. The Eco-Industrial Park at Kalundborg, Denmark is one of the first by-product exchanges to utilize an exchange of waste heat in the form of steam between companies. These exchanges offset a large amount of energy each year while still contributing to each company's bottom line (Jacobsen, 2006). In the Netherlands, combined heat and power (CHP) plants have been used for many years to provide space heating to local greenhouse farmers, and in many cases are owned by either individual greenhouses or associations of smaller farmers. The greenhouse sector in the Netherlands is now a net energy exporter, with 2,500 MW of CHP capacity associated with greenhouses (Nederhoff, 2008). In addition, The Kiawana Industrial complex in Australia recently performed an energy assessment of its industries and determined that there was the potential to mitigate up to $7 \%$ of the total $\mathrm{CO}_{2}$ emissions of the local industrial park through the effective use of flue gas waste heat (Beers and Biswas, 2008).

Many other organizations worldwide utilize energy exchanges in the form of steam and combustion products from industries, in addition to utility sharing through the communal use of a large-scale CHP plant (Nederhoff, 2008). These systems were found to be profitable, in a recent study performed by the U.S. Department of Energy on energy loss reduction, the effective use of industrial waste heat was at the top of the list of recommendations, and had the possibility of diverting the use of 828 trillion BTUs of energy with an associated economic value of \$2.210 trillion within the United States (Incorporated Energetics, 2004).

Greenhouses are a logical choice for utilizing the available exergy provided by industrial operations for a number of industry-specific reasons. They require heat at a relatively low temperature to maintain ambient conditions and they are therefore able to effectively utilize a large portion of the available enthalpy even from temperature sources which are lower than combustion temperatures, such as flue gases. Additionally, if appropriate emissions controls are implemented the exhaust gases from the heat emitting source, which contain $\mathrm{CO}_{2}$ required by biological plants for growth, can potentially be sold to 
Published: R. Andrews and J.M. Pearce, "Environmental and Economic Assessment of a Greenhouse Waste Heat Exchange”, Journal of Cleaner Production 19, pp. 1446-1454 (2011). http://dx.doi.org/10.1016/j.jclepro.2011.04.016

the greenhouse, at an economic benefit to both companies.

There are, however, risks associated with the implementation of a waste heat greenhouse. The largest risk is the possibility of an intermittent source of heat either due to an unreliable process, or else a reduced production run in the supplying company. This is mitigated by the use of a backup heat source. Additionally, a greenhouse would be closely tied to the industrial operation. If the plant were to shut down before the greenhouse was able to recuperate their capital costs for the Waste Heat Boiler (WHB) system, the greenhouse may have a hard time transitioning back to a pure natural gas system. Specific to the proposed exchange between a glass manufacturer and tomato greenhouse, if the flue gasses were used as $\mathrm{CO}_{2}$ enrichment, there could be concerns of heavy metal contamination in the food if there are any issues with the emissions reductions equipment. Even if these are not to a level to be a health risk, the perceived risk of the produce may significantly effect its competitiveness.

\subsection{The Glass Industry}

The glass industry was chosen for this case study because of its large quantity of available waste heat combined with its use of natural gas furnaces, which could allow the use of flue gasses as $\mathrm{CO}_{2}$ enrichment if appropriate filtration technologies were employed. There are, however, many industries with which a greenhouse could be coupled, including pulp and paper, aluminum smelting, and combined heat and power operations. The focus on the glass industry is meant to act as a case study to highlight the methodology for assessing such projects.

The glass industry is divided into two major sections: i) flat glass and ii) pressed and blown glass. Flat glass is used primarily for fenestration, automotive, and as a front a back cover for solar photovoltaic modules. Pressed and blown glass is seen in containers, lamps and other three dimensional designs (World Bank Group, 1998). The following example uses data for a typical flat glass plant, however it important to emphasize again that the purpose of this case study is to show the applicability of a greenhouse waste heat exchange with any energy intensive industry. The purpose for focusing on a specific industry is to offer an appropriate "lens" to highlight the advantages and issues with such a system.

Flat glass manufacturing combines silica, lime, dolomite, soda and cullet (recycled glass) along with specialized additives for specific glass properties, in high temperature furnaces powered primarily by natural gas burners (World Bank Group, 1998). Modern flat glass plants use a float glass technique, where raw materials are added in one end of the furnace while appropriately mixed and melted product is extracted from the other end of the furnace allowing continuous firing. Some furnaces will use an electric boost by passing current through the glass using submerged electrodes near the finished end of the float glass furnace to improve the efficiency of the process. In float glass manufacturing electrical boost provides only $10 \%-30 \%$ of the total heat (Worrell et al., 2008).

Traditional and efficient air-fuel furnaces will typically use a fixed-bed regenerator to preheat combustion air entering the furnace. These devices typically work in pairs: the exhaust gasses are passed through a regenerator composed of an aluminum or ceramic heat storage elements (refractory bricks, or aluminum balls, generally) where heat from the exhaust gasses is transferred to these media. 
Published: R. Andrews and J.M. Pearce, "Environmental and Economic Assessment of a Greenhouse Waste Heat Exchange”, Journal of Cleaner Production 19, pp. 1446-1454 (2011). http://dx.doi.org/10.1016/j.jclepro.2011.04.016

The direction of airflow is then reversed after a given interval, forcing the cool inlet air to pass over the heated heat transfer media. The flue gas is similarity redirected into the regenerator that was previously used as a cold air inlet. In this way the combustion air is heated and the flue gasses are cooled. It is assumed that a cooling of the flue gasses from approximately $1450{ }^{\circ} \mathrm{C}$ to $450{ }^{\circ} \mathrm{C}$ is possible with the use of a regenerator (Kobayashi et al., 2005; Reay, 1979; Richards, 1980). Because of the size and complexity of these regenerator systems for flat glass furnaces, they tend to be used in furnaces of larger capacity and generally will produce 100-1000 tons of flat glass per day (Pellegrino et al., 2002).

A new technology is emerging with the use of oxygen enriched firing of glass furnaces. As less energy is required to heat the surrounding air (which is mostly nitrogen) more heat is available for transfer into the molten glass. Additionally, because there is less available nitrogen, the development of nitrous oxide is dramatically reduced (Kobayashi et al., 2005). Typically oxy-fueled furnaces will have a higher flue gas temperature with a lower flue gas volume; because of the lack of nitrogen, there will be a lower volumetric flow rate of combustion air required to achieve the same equivalence ratio. This lover volumetric flow rate will be carrying the same enthalpy, and therefore will be at a higher temperature (Kobayashi et al., 2005). Because of the higher portion of enthalpy is available at a greater temperature differential, the amount of enthalpy which can be extracted from this flue gas stream is greater than a traditional regenerative air fueled furnace. However, only an air-fueled furnace is considered in this study.

\subsection{The Greenhouse Industry}

\subsubsection{Overview}

The purpose of a greenhouse is to allow the cultivation of horticultural crops outside of their traditional climactic zones and requirements. For example, in Canada greenhouses are used to provide "hot house" tomatoes essentially year round to compete against imported produce from countries with more favorable climactic conditions (primarily the U.S. and Mexico, though there are some overseas imports as well) (Agriculture Canada, 2008). Greenhouse tomatoes have some distinct advantages over imported produce, because the produce is grown close to their final markets they can be allowed to ripen on the vine, improving their flavor compared to imported produce which must ripen in transit. Additionally, because the produce is grown locally, the transportation costs and embodied energy of transportation (Pearce et al., 2007) are not as great, and they benefit from the new trend of "buy local" campaigns in Canada. The greenhouse industry in Ontario is the largest in Canada, accounting for over 11 million square meters of covered land, or more than half of Canada's total 21 million square meters of covered land. This industry produces both vegetable and agricultural products, with tomatoes being the most highly produced vegetable in Ontario at 3 million square meters, and the total of floricultural crops equaling over 4 million square meters (Statistics Canada, 2008).

There are disadvantages to northern greenhouses, however, which have caused the industry to move towards larger operations; in Canada from 2007 to 2009 the average size of vegetable greenhouses has increased by $12 \%$ from 1.49 to 1.7 acres and in Ontario, the province which produces the majority of greenhouse products in Canada, the average greenhouse size has increased by $10 \%$ from 2.37 acres to 2.63 acres (Statistics Canada, 2008). The largest barrier to these operations is the volatility of heating prices, which can account for $15 \%-20 \%$ of a greenhouse operation (Statistics Canada, 2008). The province of Alberta in Canada has kept accurate records of the average monthly reference price for 
Published: R. Andrews and J.M. Pearce, "Environmental and Economic Assessment of a Greenhouse Waste Heat Exchange”, Journal of Cleaner Production 19, pp. 1446-1454 (2011). http://dx.doi.org/10.1016/j.jclepro.2011.04.016

natural gas since 1988. Since 2003, the average price for natural gas is $\$ 6.04 / G J$, with a minimum of $\$ 2.48 / G J$ and a maximum of \$11.38/GJ (Government of Alberta, 2010). These fluctuations in operating costs are difficult to pass along to the consumer while still staying competitive. Additionally, a recent report by the energy information agency has predicted that this average cost is expected to increase dramatically in the future (EIA, 2009).

The pressures caused by increased competition of international suppliers coupled with increasing energy costs especially in natural gas, have caused many greenhouses to move to alternative fuel sources (Nederhoff and Houter, 2008). The most prevalent alternative fuels used in northern climates are fuel oil and biomass, although there is also an emergence of combined heat and power (CHP). The emissions of biomass on a greenhouse burner scale are not appropriate for direct injection into the greenhouse for use in $\mathrm{CO}_{2}$ enrichment because of the presence of dangerous pollutants, requiring the use of supplemental liquefied $\mathrm{CO}_{2}$ or natural gas $\mathrm{CO}_{2}$ generators (Chau et al., 2009). CHP is another method which is commonly used in the Netherlands for greenhouse heating, and currently has 2,500 MW of greenhouse tied CHP (Nederhoff and Houter, 2008). Because CHP systems burn either natural gas or bio gas, the emissions can be treated for nitrous oxide emissions and be injected directly into the greenhouse for $\mathrm{CO}_{2}$ enrichment. These greenhouse tied CHP systems are gaining a hold in Canada, with the recent commissioning of a 50 acre greenhouse run from a CHP generator in Ontario (Soave Enterprises, 2009).

The use of industrial waste heat for greenhouse heating is not a new idea. In the 1970's to the early 1980 's there was a push towards the increased use of industrial waste heat, and several test greenhouses were opened, tied to either large scale power plants or industrial operations. In Saskatchewan, for example, two greenhouses were set up to run from the exhaust gasses from booster compressor stations along the national natural gas pipeline. Though these projects met with initial success, they later ceased operation which is assumed to be attributed to the variable quality of the heat supply (Weseen, 2001). The Shand power station in Saskatchewan opened a waste heat greenhouse in 1991, and is continuing to grow tree seedlings for use as a carbon offset (SaskPower, 2010). In addition, several studies have previously investigated the feasibility of using waste heat from power generation facilities, and in some cases have constructed test greenhouses (Manning and Mears, 1981; Helgeson et al., 1986; Olszewski, 1978).

\subsubsection{Greenhouse structure}

Greenhouses are generally made of a clear glass or plastic, which allows the passage of most of the solar spectrum for plant photosynthesis, but prevents infrared photons from crossing. When the visible light is absorbed by the foliage in the greenhouse, it is changed and is re-radiated primarily in the infrared range, and so a large portion of the solar energy entering the greenhouse is retained. There are many different structural designs for greenhouses, the most common is the straight sidewall with a gable roof because of its simple framing and efficient use of standard building materials. In a commercial application, multiple structures are connected together in a gutter-connected arrangement and the interior walls are eliminated. This reduces the external surface area of the structure and therefore reduces the heating load on the structure. In northern climates, it is recommended by the American Society of Agricultural and Biological Engineers (ASABE) to provide heating at the gutters to reduce snow build-up (2008). 
Published: R. Andrews and J.M. Pearce, "Environmental and Economic Assessment of a Greenhouse Waste Heat

Exchange”, Journal of Cleaner Production 19, pp. 1446-1454 (2011). http://dx.doi.org/10.1016/j.jclepro.2011.04.016

\subsubsection{Greenhouse Requirements}

The requirements of a commercial greenhouse are listed below (Tiwari, 2003):

Electricity: A large scale greenhouse operation requires three phase power. This is particularly important if supplementary lighting is used to increase crop yield.

Land: Greenhouses have a large footprint and require a large amount of relatively flat land. Space should also be available for expansion if the marke $t$ demands it. Some cost reductions can be achieved if the topsoil in the area used for a greenhouse is of high enough quality to act as potting soil, if soil cultivation is used in the greenhouse.

Water: Access to large volumes of clean water is essential for a commercial operation.

Access to Markets: In order to reduce transportation costs the greenhouse should be located in close proximity to its final markets. This decreases costs as well as reduces the possibility of damage to the ripened produce during transportation

Heat Supply: A heat supply is traditionally provided by natural gas (the most common method), fuel oil or coal, but can be supplied by industrial waste heat.

\section{Methodology}

The purpose of this paper is to demonstrate a methodology to determine the maximum yield of produce that can be grown while being supported by the waste heat from a large float glass manufacturing plant. This methodology has the following structure:

- Determine the availability of waste heat that can be extracted from the flue gas taking into account thermodynamic and practical considerations.

- Utilize previously derived models for greenhouse heating requirements to calculate the largest size of greenhouse that can be supported at a threshold temperature. This technique involves a novel method of transforming the greenhouse energy model into a parametric equation to determine the maximum supported area of a greenhouse for a given quantity of waste heat.

- Use greenhouse productivity information to predict the potential yield from this operation.

- Use representative solar irradiation and temperature data in previously derived models for greenhouse heat losses to determine the actual heat load absorbed by the greenhouse, and calculate the amount of $\mathrm{CO}_{2}$ offset from the use of industrial waste heat.

- Utilize information on energy and $\mathrm{CO}_{2}$ requirements to perform a basic Net Present Value (NPV) comparison between waste heat and fossil fuel heating.

\subsection{Waste heat availability}

The amount of available waste heat was calculated for a typical float glass plant assessed by the U.S. Department of Energy's Industrial Assessments Center database, which contains energy usage in terms of BTU's of natural gas burnt, and also provides information on the company's size and revenue. The plant chosen for this study produces 500 tons of glass per day, making it a mid-sized float glass operation (Pellegrino et al., 2002), and utilizes 1.25 PJ of natural gas a year (IAC, 2007). The entire 
Published: R. Andrews and J.M. Pearce, "Environmental and Economic Assessment of a Greenhouse Waste Heat Exchange”, Journal of Cleaner Production 19, pp. 1446-1454 (2011). http://dx.doi.org/10.1016/j.jclepro.2011.04.016

waste heat system is shown in Figure 1, which shows the proposed structure and energy flows:

Figure 1: Proposed waste heat system, showing system structure and energy flows.

The total power available in the waste heat stream was determined from:

$$
E_{f}=\left[\frac{Q_{t}}{S_{y}}\right] \varepsilon_{\text {util }} \varepsilon_{\text {flueloss }}
$$

Where $E_{f}(\mathrm{~W})$ is the total power available in the flue gas, $Q_{t}(\mathrm{~J})$ is the total yearly energy consumed by the plant, $\mathrm{S}_{\mathrm{y}}(\mathrm{s})$ is the total operational time in seconds for the plant in a year, $\varepsilon_{\text {util }}$ is the total fraction of the energy which is utilized in the furnace, and $\varepsilon_{\text {flueloss }}$ is the fraction of energy consumed in the furnace which is released through the flue gas.

It is assumed that other North American glass manufacturers will have a similar energy usage profile and that $95 \%$ of this natural gas will be burnt in the furnace for glass production, with the rest being used in the plant for glass annealing and other smaller heating tasks (Reay, 1979). A typical air fired regenerative furnace transfers only $50 \%-60 \%$ of the heat from combustion to the melt, this metric is generally referred to as the furnace efficiency (OIT, 2002), however, efficiencies as low as $42 \%$ have been recorded (Arican and Hortaçsu, 1992) depending on the insulation and configuration of the furnace. The waste heat is divided between convection and radiation losses from the furnace and heat rejected in the flue gasses. It is generally assumed that $30 \%$ of the energy is rejected through the flue gas, (Pellegrino et al., 2002; Khinkis, 1968; Nycz and Sturgill, 1980; Hnat 1985). Therefore, using these values in equation (1) and assuming $100 \%$ plant uptime, a maximum of $11.3 \mathrm{MW}$ of power is available in the flue gas in the case study.

In order to determine the energy available for recovery in the flue gas, combustion was assumed to have $10 \%$ excess air, and the natural gas was assumed to be a blend of $80 \%$ methane and $20 \%$ ethane. The general combustion equation, ignoring production of $\mathrm{CO}, \mathrm{NO}_{\mathrm{x}}$, and assuming complete combustion is:

$$
\left(0.8 \mathrm{CH}_{4}+0.2 \mathrm{C}_{2} \mathrm{H}_{6}\right)+Y\left(0.79 \mathrm{~N}_{2}+0.21 \mathrm{O}_{2}\right)=a \mathrm{CO}_{2}+b \mathrm{H}_{2} \mathrm{O}+c \mathrm{O}_{2}+d \mathrm{~N}_{2}
$$

From equation (2), the stoicheometric air fuel ratio (AFR) is 10.95. At $10 \%$ excess air, this becomes close to 12. Solving the equation for this AFR, the composition of the flue gas is found to be $72.9 \%$ nitrogen, $16.7 \%$ water, $9 \%$ carbon dioxide, and $2 \%$ oxygen (by mol). Assuming that the products of combustion are at atmospheric pressure, the dew point of water is $55^{\circ} \mathrm{C}$.

The total recoverable power from the waste heat stream is limited by the achievable temperature drop in the flue gas, and can be summarized in the following equation:

$$
E_{r}=\left[\frac{E_{f}}{h_{f g}}\right]\left[h_{f g}-h_{e x t}\right]
$$

Where $h_{f g}$ is the enthalpy contained in the flue gas as it leaves the furnace regenerator in $\mathrm{kJ} / \mathrm{kmol}, h_{\mathrm{ext}}$ is the enthalpy contained in the flue gas at the exit of the waste heat boiler and $E_{r}$ is the total recoverable 
Published: R. Andrews and J.M. Pearce, "Environmental and Economic Assessment of a Greenhouse Waste Heat Exchange”, Journal of Cleaner Production 19, pp. 1446-1454 (2011). http://dx.doi.org/10.1016/j.jclepro.2011.04.016

power in the waste heat stream, in $\mathrm{W}$.

An important factor to consider when recovering energy from waste heat streams is the acid dew point of the gasses, and the condensation of sodium sulphate salts vaporized from the glass melt, which can foul heat transfer surfaces (Hnat et al., 1985; Richards, 1980). The lowest allowable stack flue gas temperature is dependent on many variables including ambient temperatures, stack insulation and height, and company policies. Accordingly, the amount of power recoverable from this flue gas stream was plotted as a function of temperature at the outlet of the waste heat recovery boiler, and is shown in Figure 2.

Figure 2: Recoverable power as a function of waste heat boiler outlet temperature

In this study, a non-condensing waste heart boiler (WHB) is considered, and previous studies have shown that a temperature of $204^{\circ} \mathrm{C}$ is generally acceptable to minimize heat exchanger fouling (Hnat et al., 1985). Accordingly, using an enthalpy drop from $450^{\circ} \mathrm{C}$ to $204^{\circ} \mathrm{C}$ and $E_{f}$ calculated in equation (3), the total power recoverable from this waste heat stream $\left(E_{r}\right)$ is $5.1 \mathrm{MW}$. This amount of waste heat is comparable to previous studies of waste heat boilers used in glass plants. A waste heat boiler installation in a 650 ton/day Swedish float glass plant being used to produce space heating water had a predicted maximum recoverable power of 6.4 MW (Richards, 1980).

The greenhouse will still require a backup natural gas boiler. This is critical, because though modern glass manufacturing is a constant process, it is probable there will be both planned and unplanned downtime during the year. For the purposes of this model, it is assumed that the plant will be unable to provide $6 \%$ of the total heat, which should be provided by the backup system.

Table 1:Data used to determine available energy

\begin{tabular}{lrl|lr}
\multicolumn{3}{c|}{ Input Data } & \multicolumn{2}{c}{ Output data } \\
\hline$Q_{t}$ & 1.25 & $P J$ & $E f$ & $5.1 \mathrm{MW}$ \\
$E_{r}$ & 11.3 & $\mathrm{MW}$ & & \\
$S y$ & 31104000 & $\mathrm{~S}$ & & \\
$\varepsilon_{\text {util }}$ & 0.95 & & & \\
$\varepsilon_{\text {flueloss }}$ & 0.3 & & \\
$h_{f g}$ & 38977 & $\mathrm{~kJ} / \mathrm{kmol}$ & & \\
$h_{\text {ext }}$ & 21386 & $\mathrm{~kJ} / \mathrm{kmol}$ & &
\end{tabular}

\subsection{Supported Greenhouse Area}

In order to calculate the potential area of a greenhouse supported from a given waste heat stream, the energy balance of the greenhouse must be understood. The full energy balance for a greenhouse is (Chalabi et al., 2002):

$$
Q=A U\left(T_{i}-T_{o}\right)+c_{\text {air }} \varphi \rho_{\text {air }}\left(T_{i}-T_{o}\right)-\beta S
$$


Published: R. Andrews and J.M. Pearce, "Environmental and Economic Assessment of a Greenhouse Waste Heat Exchange”, Journal of Cleaner Production 19, pp. 1446-1454 (2011). http://dx.doi.org/10.1016/j.jclepro.2011.04.016

Where A is the total surface area of the structure $\left(\mathrm{m}^{2}\right), \mathrm{U}$ is the heat loss coefficient of the structure $\left(\mathrm{W} / \mathrm{m}^{2} \mathrm{~K}\right), \mathrm{C}_{\text {air }}$ is the specific heat of the air $(\mathrm{J} / \mathrm{kgK}), \varphi$ is the ventilation rate $\left(\mathrm{m}^{2} / \mathrm{s}\right), \varphi_{\text {air }}$ is the density of the air $\left(\mathrm{kg} / \mathrm{m}^{2}\right), \quad \beta$ is the fraction of the incident light absorbed by the canopy, $\mathrm{S}$ is the total solar irradiation over the greenhouse (W), and $T_{i}$ and $T_{o}$ are the internal and external temperatures $(\mathrm{K})$ respectively. This equation is simplified somewhat by ASABE for the purposes of sizing a heating system, and the solar irradiation term is dropped. The equation becomes:

$$
E_{r}=A U\left(T_{i}-T_{o}\right)+1800 V N\left(T_{i}-T_{o}\right)
$$

where $\mathrm{V}$ is the greenhouse volume $\left(\mathrm{m}^{3}\right)$ and $\mathrm{N}$ is the ventilation rate $\left(\mathrm{s}^{-1}\right)$, tabulated by ASABE and assumed to be $2.1 \times 10^{-4} \mathrm{~s}^{-1}$, which is mid range for a new glass or plastic installation (ASABE, 2008). The thermal coefficient, $\mathrm{U}$, was determined to be $4 \mathrm{~W} / \mathrm{m}^{2} \mathrm{~K}$ which is the upper range of suggested coefficients for new double walled plastic or glass structures (Chau et al., 2009; Garzoli and Blackwell, 1987; ASABE, 2008). It should be noted that by using a thermal blanket, this value can be reduced to $2.5 \mathrm{~W} / \mathrm{m}^{2} \mathrm{~K}$ (ASABE, 2008). The external temperature was taken to be the $99 \%$ dry bulb temperature suggested by the American Society of Heating, Refrigerating, and Air-Conditioning Engineers for Kingston Ontario, which is $-24^{\circ} \mathrm{C}$. The optimal internal temperature $\left(\mathrm{T}_{\mathrm{i}}\right)$ for growing tomatoes is $21^{\circ} \mathrm{C}$ (Jones, 1999), and has been used in previous waste heat greenhouse modeling methodologies, (Manning and Mears, 1981). The heating system is designed to maintain this temperature at night even on the coldest days of winter.

In order to determine the total supported area for the greenhouse, equation (5) was first expressed in terms of the linear dimension of the greenhouse, dimension L in Figure 1:

$$
E_{r}=\left(4 L h+\frac{L^{2}}{\cos (\theta)}\right) U\left(T_{i}-T_{o}\right)+1800\left(h+\frac{G}{2}\right) L^{2} N\left(T_{i}-T_{o}\right)
$$

Where $h$ is the height of the greenhouse, assumed to be $4 \mathrm{~m}, \theta$ is the roof pitch angle, assumed to be $30^{\circ}$ and $G$ is the length of a side of the pitched roof assumed to be $2 \mathrm{~m}$ (see Figure 1). Re-arranging the quadratic to solve for the linear dimension gives:

$$
L=\frac{-4 h U \Delta T+\sqrt{(4 h U \Delta T)^{2}-4\left\{\left(H+\frac{G}{2}\right) 1800 N \Delta T+\frac{U \Delta T}{\cos (\theta)}\right\}\left(-E_{r}\right)}}{2\left\{\left(H+\frac{G}{2}\right) 1800 N \Delta T+\frac{U \Delta T}{\cos (\theta)}\right\}}
$$

It was found that, based on these conservative assumptions, the flat glass plant could support a 3.9 acre greenhouse operation. This is larger than the average greenhouse size in Canada, however there are examples of greenhouses which utilize centralized heat sources such as industrial waste heat or CHP being as large as 50 acres (Soave Enterprises, 2009).

Table 2: Data used in the calculation of total supported area of the greenhouse 
Published: R. Andrews and J.M. Pearce, "Environmental and Economic Assessment of a Greenhouse Waste Heat Exchange”, Journal of Cleaner Production 19, pp. 1446-1454 (2011). http://dx.doi.org/10.1016/j.jclepro.2011.04.016

\begin{tabular}{|lrl|lll|}
$\mathrm{U}$ & 4 & $\mathrm{~W} / \mathrm{m} 2 \mathrm{~K}$ & $\mathrm{~L}$ & 137 & $\mathrm{~m}$ \\
$\mathrm{Ti}$ & 21 & ${ }^{\circ} \mathrm{C}$ & Area & 3.99 & acres \\
$\mathrm{To}$ & -24 & ${ }^{\circ} \mathrm{C}$ & & & \\
$\mathrm{N}$ & $2.10 \mathrm{E}-04$ & $\mathrm{~s}-1$ & & & \\
$\mathrm{~h}$ & 4 & $\mathrm{~m}$ & & & \\
$\mathrm{G}$ & 2 & $\mathrm{~m}$ & & & \\
$\theta$ & 30 & ${ }^{\circ}$ & & & \\
\hline
\end{tabular}

\subsection{Carbon Dioxide Enrichment}

Modern greenhouse operations utilize $\mathrm{CO}_{2}$ enrichment in order to increase crop yields. Especially in a tightly sealed greenhouse being heated in the winter time, $\mathrm{CO}_{2}$ enrichment is required at the minimum to maintain the atmospheric concentration of $\mathrm{CO}_{2}$ at ambient levels (around $380 \mathrm{ppm}$ ) to account for plant photosynthesis (Chalabi, et al., 2002a). It has been shown, however, that crop yields will increase up to $\mathrm{CO}_{2}$ concentrations of 1000 ppm and increases in yields up up to $90 \%$ have been recorded for $\mathrm{CO}_{2}$ greenhouse tomatoes (Nilsen et al., 1983).

There are two common methods for delivering $\mathrm{CO}_{2}$ enrichment; through the injection of combustion products or through the use of liquid $\mathrm{CO}_{2}$. The combustion products from natural gas burned at an equivalence ratio optimized for low $\mathrm{NO}_{\mathrm{x}}$ and $\mathrm{CO}$ production and with good mixing for complete combustion can be directly injected into a greenhouse for $\mathrm{CO}_{2}$ enrichment due to the high purity of natural gas, the only treatment required is a flue gas condenser to remove some of the moisture from the flue gasses to control the relative humidity of the greenhouse for fungal reasons (Chalabi et al., 2002).

It should be noted that combustion for gas turbines or reciprocating engines (as in a CHP unit) or in industrial burners typically occurs at an equivalence ratio different from this optimal value, requiring the use of emissions control technologies, such as urea injection and selective catalytic reduction (SCR) to reduce these to acceptable values, and this is discussed more fully in section 4 . This difference is primarily because the design parameters for these systems include factors other than only emissions reductions, and therefore, will generally have higher emissions levels than a dedicated natural gas burner. This method of $\mathrm{CO}_{2}$ enrichment has the advantage that it is essentially "free" $\mathrm{CO}_{2}$, as the flue gasses are already developed in the process of burning the natural gas. However, an issue arises as the $\mathrm{CO}_{2}$ demand profile is generally the opposite of the heating demand profile; the times that the most $\mathrm{CO}_{2}$ is required is during the highest rate of photosynthesis and therefore there is a large amount of solar irradiation heating the greenhouse, and heating demand is low. To remedy this, some installations utilize fluid thermal storage, where the heating system will heat water during the day, and produce $\mathrm{CO}_{2}$ for use in the greenhouse. At night, the hot water is used to heat the greenhouse (Chalabi et al., 2002).

The use of liquid $\mathrm{CO}_{2}$ eliminates this requirement, but requires that the $\mathrm{CO}_{2}$ is purchased from a third party and transported to the site, at a higher expense. The advantage, however, is that it is possible to maintain the ideal atmospheric $\mathrm{CO}_{2}$ concentration at any given time. This strategy has been shown to provide a marginal increase in revenues of up to $27 \%$, and requires $67 \mathrm{~kg}$ of $\mathrm{CO}_{2} / \mathrm{m}^{2}$ of greenhouse per year (Chalabi et al., 2002). Based on the size of the proposed greenhouse, this corresponds to 1,083 $t$ $\mathrm{CO}_{2} /$ year required for the proposed greenhouse. 
Published: R. Andrews and J.M. Pearce, "Environmental and Economic Assessment of a Greenhouse Waste Heat Exchange”, Journal of Cleaner Production 19, pp. 1446-1454 (2011). http://dx.doi.org/10.1016/j.jclepro.2011.04.016

\subsection{Determining heating energy and carbon offset}

The calculated supported area is the maximum area that can be heated at the maximum greenhouse heat loss, namely at night on the coldest day of the year. However, the actual heating demand for the majority of the year will be much lower than this maximum value. To account for this, the average hourly energy demand was calculated for an entire year taking into account both the average external temperature and solar irradiation. Hourly averaged temperature information was taken from the Energy Plus weather information database for Kingston, ON (USDoE, 2009), and hourly averaged solar irradiation data was collected locally from the Queen's University Integrated Learning Center solar array (Queen's University, 2009). This information was used to solve for the total required heat ( $\left.Q_{\text {actual }}\right)$ measured in J according to (Chalabi et al., 2002):

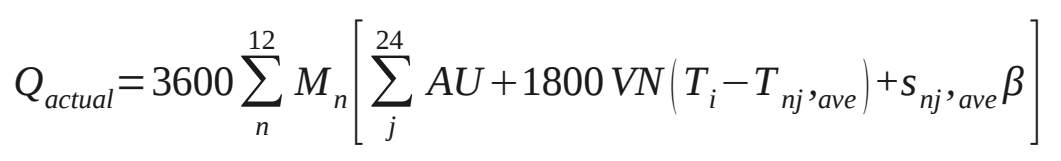

where $M_{n}$ is the number of days in month $n, T_{n j}$, ave is the hourly average temperature at hour $j$ in month $n$ and $S_{n j, a v e}$ is the hourly average solar irradiation (W) over the entire greenhouse structure in month $n$. $\beta$ was taken to be 0.71 , which is the absorptivity of a tomato greenhouse canopy (Zhang, 1997). At any time that the heating load was found to be negative (active cooling is required) it was assumed that the greenhouse would be ventilated, and therefore there would be no natural gas requirement. The overall heating load profile is shown in Figure 3.

Figure 3: Monthly heating requirement for a southern Ontario greenhouse.

Integrating the curve in Figure 3 produces a total heat requirement of 34,562 GJ/year. Assuming $50 \mathrm{~kg}$ of $\mathrm{CO}_{2}$ is developed from a GJ of natural gas combustion (U.S. EPA, 1995) this corresponds to a total offset of 1,728 tonnes of $\mathrm{CO}_{2}$ /year by using industrial waste heat. In order to determine the net gain of carbon emissions over a traditional natural gas system, three situations must be analyzed. The first is when the natural gas greenhouse utilizes liquefied $\mathrm{CO}_{2}$, which means that both greenhouses will have the same heating profile and level of $\mathrm{CO}_{2}$ injection, resulting in a net reduction of 1,728 tonnes of $\mathrm{CO}_{2}$ purely from the reduction in heating fuels. The second situation is if the natural gas greenhouse utilizes combustion $\mathrm{CO}_{2}$ while the waste heat greenhouse utilizes liquefied $\mathrm{CO}_{2}$. In this case, previous studies have shown that the natural gas greenhouse will increase its fuel usage by up to $43 \%$ (Chalabi et al., 2002). Therefore, the total $\mathrm{CO}_{2}$ emissions for the natural gas greenhouse is 2,125 tonnes, implying that the waste heat greenhouse now accounts for a carbon savings of 1,042 tonnes of $\mathrm{CO}_{2}$, as the waste heat greenhouse is still using 1,083 tonnes of liquefied $\mathrm{CO}_{2}$. The final case to consider is if both greenhouses use combustion $\mathrm{CO}_{2}$, in which case the total offset is equal to 2,125 tonnes of $\mathrm{CO}_{2}$. Thus, the total carbon offset can range from 1,042 tonnes to 2,125 tonnes per year depending on assumptions being made about the greenhouse being replaced.

\subsection{Predicted yields and economic value}

The determination of the predicted yields from the greenhouse is important to estimate the possible revenue stream from the greenhouse. Two Ontario waste heat greenhouses were analyzed for their 
Published: R. Andrews and J.M. Pearce, "Environmental and Economic Assessment of a Greenhouse Waste Heat

Exchange”, Journal of Cleaner Production 19, pp. 1446-1454 (2011). http://dx.doi.org/10.1016/j.jclepro.2011.04.016

yields, i) Bruce Tropical Produce Inc. which utilizes the waste heat from the Bruce nuclear plant yields 175 tonnes per acre year of tomatoes (Bruce County, 2009) and ii) Great Northern Hydroponics, a 50 acre greenhouse tied to a natural gas CHP unit produces 184 tonnes per acre year (Soave Enterprises, 2009). According to statistics Canada, the average tomato price in 2008 was $\$ 0.81$ per pound (Statistics Canada, 2008). Based on the calculated size of the case study greenhouse, and using the higher yield prediction, as modern techniques and $\mathrm{CO}_{2}$ enrichment will be used, this corresponds to a yield of 735 tonnes of tomatoes with an economic value of $\$ 1.3$ million per year.

\section{Economic Analysis}

In order to determine the economic viability of the use of a waste heat greenhouse in the current economic climate, a Net Present Value (NPV) analysis was performed. The entire greenhouse was not considered in this analysis, only the heating system, with the assumption being that all other operating costs would remain the same. Therefore a positive difference in NPV represents the economic gains for a greenhouse operation utilizing waste heat as compared to a traditional natural gas burner.

The required energy is $\mathrm{Q}_{\text {act }}$ and $\mathrm{CO}_{2}$ needed is calculated in section 2.4, and the $\mathrm{CO}_{2}$ costs are based on estimates of $\$ 200 /$ ton (Chau, 2008). The analysis is performed as a comparison between a traditional natural gas boiler and a waste heat greenhouse. The natural gas system is designed with the following assumptions: i) the heater is a boiler feeding hot water to ground level tubing in the greenhouse, thus all pumping and capital costs associated with the floor heating system are the same between both systems; ii) the natural gas burner is vented to the outdoors, and thus does not provide $\mathrm{CO}_{2}$ for the greenhouse, and transfers heat to the greenhouse with a thermodynamic efficiency of $85 \%$, defined as the ratio of the enthalpy transferred to the greenhouse through the heat exchanger to the chemical energy available in the natural gas. The waste heat system is assumed to have a waste heat boiler, a backup natural gas boiler, and piping to the greenhouse. 
Published: R. Andrews and J.M. Pearce, "Environmental and Economic Assessment of a Greenhouse Waste Heat Exchange”, Journal of Cleaner Production 19, pp. 1446-1454 (2011). http://dx.doi.org/10.1016/j.jclepro.2011.04.016

Table 3: Economic analysis, base numbers

\begin{tabular}{|c|c|}
\hline \multicolumn{2}{|c|}{ Base Values for NPV calculation } \\
\hline Project lifetime & 20 \\
\hline MARR & $10 \%$ \\
\hline \multicolumn{2}{|l|}{ Natural gas burner } \\
\hline \multicolumn{2}{|l|}{ Annual Costs } \\
\hline Cost of natural gas $(\$ / G J)$ & $\$ 6$ \\
\hline Required energy, including inefficiencies (GJ/year) & 39,088 \\
\hline $\mathrm{CO}_{2}$ costs (Chau, 2008) & $\$ 243,473.54$ \\
\hline Total annual costs & $\$ 478,000.34$ \\
\hline \multicolumn{2}{|l|}{ Capital costs } \\
\hline Natural gas burner and backup (\$/MW) (Chau, 2008) & $\$ 30,000.00$ \\
\hline Total capital costs & $\$ 153,000.00$ \\
\hline \multicolumn{2}{|l|}{ Waste heat system } \\
\hline \multicolumn{2}{|l|}{ Annual Costs } \\
\hline Backup Natural Gas (6\% of total load) & 2,345 \\
\hline Natural gas costs & $\$ 14,071.61$ \\
\hline $\mathrm{CO}_{2}$ costs (Chau, 2008) & $\$ 243,473.54$ \\
\hline Total annual costs & $\$ 257,545.15$ \\
\hline \multicolumn{2}{|l|}{ Capital costs } \\
\hline Waste heat boiler (\$/MW) (Beers, 2008) & $\$ 150,000.00$ \\
\hline Pipe system (Helgeson et al., 1986) & $\$ 310,662.00$ \\
\hline Backup burner (\$/MW) (Chau, 2008) & $\$ 15,000.00$ \\
\hline Total capital costs & $\$ 1,152,162.00$ \\
\hline \multicolumn{2}{|l|}{ NPV comparison } \\
\hline NPV (waste heat) & $\$ 3,344,789.05$ \\
\hline NPV (Natural Gas) & $\$ 4,222,486.32$ \\
\hline Difference & $\$ 877,697.28$ \\
\hline
\end{tabular}

Because of the variability of the inputs to the NPV calculation, a sensitivity analysis for a range of expected energy prices was performed. The effects of this variation are shown for the base case, an increase in Minimum Acceptable Rate of Return (MARR) to 15\%, an increase in capital costs for the waste heat system of $20 \%$ and $50 \%$ and comparison with a natural gas burner using combustion $\mathrm{CO}_{2}$. It should be noted here that these MARR values are extremely aggressive given the current global economic situation. The results of this sensitivity analysis can be seen in Figure 4 that a greenhouse utilizing combustion $\mathrm{CO}_{2}$ is much more susceptible to fluctuations in the price of natural gas.

Figure 4: Sensitivity analysis of economic advantages of a waste heat greenhouse

From Figure 4 it can be seen that in most cases over the entire campaign the waste heat greenhouse is more economical than the natural gas greenhouse. This is similar to the results shown in a previous 
Published: R. Andrews and J.M. Pearce, "Environmental and Economic Assessment of a Greenhouse Waste Heat Exchange”, Journal of Cleaner Production 19, pp. 1446-1454 (2011). http://dx.doi.org/10.1016/j.jclepro.2011.04.016

economic comparison from the 1970s, which showed that traditional fossil fuel heating was more expensive in all but very mild climates (Olszewski et al., 1976). However, in the case that the natural gas greenhouse utilizes combustion $\mathrm{CO}_{2}$ the break-even point is much higher than the other cases. It should be noted that in general, combustion $\mathrm{CO}_{2}$ does not produce as high of a crop yield as liquid $\mathrm{CO}_{2}$, as it is more difficult to achieve enrichment set points without also effecting the greenhouse temperature and therefore the revenues from these two techniques may be different. Additionally, the steeper slope of this line suggests that a greenhouse utilizing combustion $\mathrm{CO}_{2}$ is much more susceptible to fluctuations in the price of natural gas, due to its higher dependence on natural gas for heating and $\mathrm{CO}_{2}$ enrichment. The production of pure industrial $\mathrm{CO}_{2}$ is spread among a variety of sources, such as natural gas, coal, other hydrocarbon sources, and as a byproduct of industrial processes such as corn-toethanol plants. Therefore the cost of pure $\mathrm{CO}_{2}$ is likely to be more sheltered from swings in natural gas costs.

\section{Synergistic Usage of Combustion $\mathrm{CO}_{2}$ for Enrichment}

As previously mentioned, the direct emissions from an air fueled regenerative glass furnace can be used for $\mathrm{CO}_{2}$ enrichment, however, they will require treatment. The combustion process can form nitrous oxide and sulfur dioxide, and depending on the glass feedstock's used there is the possibility of trace elements of heavy metals and fluorides coming from the glass cullet being melted in the furnace (World Bank Group, 1998). Therefore, it can be seen that emissions reductions technologies must be used to reduce these harmful emissions to acceptable levels unless non-food based agriculture is practiced. In order to achieve this selective catalytic reduction will be needed to reduce the nitrous oxide emissions. In addition, a scrubber should be used to reduce the sulfur content of the gasses, depending on the quality of natural gas used. Finally, a method of reducing the heavy metals concentrations should be implemented.

These emissions control techniques represent a large capital investment for a company who is considering them. However, in the specific case study considered here, the company is spending $\$ 243,473$ on the purchase of liquefied $\mathrm{CO}_{2}$. Over a 20 year campaign at a $10 \%$ MARR this translates to a present worth of \$2.1 Million, which could help to offset a large portion of the emissions reduction infrastructure for the plant. Therefore, the implementation of a waste heat greenhouse can help to reduce the costs of compliance to future emissions legislation. Future work can look at these control technologies in more detail.

\section{Implementation Strategies}

The specific implementation of a waste heat greenhouse would depend heavily on specific circumstances. In some cases an industry may decide to purchase a greenhouse as a method of increasing revenues, whereas in another case a greenhouse may approach an industry and fund the required plant retrofits to secure an inexpensive source of heat. Regardless of the specific implementation, there are well documented procedures that are effective at bringing together traditionally disparate companies to engage in a by-product exchange. In general an intermediary body is required to initiate dialogue between stakeholder companies, which can be assisted though the use of an open source mapping methodology (Doyle and Pearce, 2009). The purpose of an intermediary body 
Published: R. Andrews and J.M. Pearce, "Environmental and Economic Assessment of a Greenhouse Waste Heat Exchange”, Journal of Cleaner Production 19, pp. 1446-1454 (2011). http://dx.doi.org/10.1016/j.jclepro.2011.04.016

is to provide relevant information and is usually an interested industry association, public sector stakeholders, environmental organizations, educational institutions, and similar organizations (Heers et al., 2004). Once the intermediary body has gathered and distributed the required information and initiated the appropriate dialogues, it is important that they allow the development of an exchange to develop organically. There have been many instances in the past where a potential exchange has failed in the planning stages or after implementation because the design of the system was monopolized by a third party and did not develop directly from the concerned parties (Desrochers, 2004).

\section{Conclusions}

This paper has presented a technical and economic methodology to determine the viability of establishing waste heat greenhouses using the waste heat from industrial processes in northern climates. Specifically, this paper investigated an exchange between a tomato greenhouse and a flat glass manufacturing plant, however the analysis and conclusions developed can be extended to any manufacturing process with a large quantity of waste heat. It has been found that a flat glass plant with a revenue production of 500 tons/day and a usage of $1.25 \mathrm{PJ}$ of natural gas can support a 3.9 acre greenhouse with a $\$ 1.3$ million annual revenue, and can offset from 1,042 to 2,125 tonnes of $\mathrm{CO}_{2}$ annually. Additionally it has been shown that over a 20 year campaign with a 10\% MARR the waste heat system is significantly less expensive to operate than a purely natural gas system. Finally, the addition of a waste heat greenhouse can reduce the costs of emissions compliance for a company, as the deferred costs of liquid $\mathrm{CO}_{2}$ can fund up to $\$ 2.1$ million of emissions reductions retrofits.

\section{References}

Agriculture Canada. 2008. Canada's Tomato Industry Report. Canada.

Arican T. and Hortaçsu Ö. 1992. Energy conservation in glass manufacture. Energy 17(6), 617-624.

ASABE. 2008. Heating, Ventilating and Cooling Greenhouses. ANSI/ASAE EP406.4 (R2008)

Beers, D. Biswas, W.K. 2008, A regional synergy approach to energy recovery: The case of the Kwinana industrial area, Western Australia. Energy Conversion and Management 49(11), 3051-3062.

Richards, B.E. 1980. Waste-Heat Boilers for Flat Glass Furnaces. Proceedings of the $40^{\text {th }}$ conference on Glass Problems. Chapter 6, 50-58.

Bruce County. 2009. Bruce Energy Centre: Bruce Tropical Produce. Published at: http://www.brucecounty.on.ca/bruceenergy.php,

Chalabi, Z.S. 1992. A generalized optimization strategy for dynamic $\mathrm{CO}_{2}$ enrichment in a greenhouse. European Journal of Operational Research 59, 308-312.

Chalabi, Z.S., Biro, A., Bailey, B.J., Aikman, D.P. \& Cockshull, K.E. 2002a. SE-Structures and Environment: Optimal Control Strategies for Carbon Dioxide Enrichment in Greenhouse Tomato Crops, Part 1: Using Pure Carbon Dioxide. Biosystems Engineering 81(4), 421-431.

Chalabi, Z.S., Biro, A., Bailey, B.J., Aikman, D.P., \& Cockshull, K.E. 2002b. SE-Structures and Environment: Optimal Control Strategies for Carbon Dioxide Enrichment in Greenhouse Tomato Crops, Part II: Using the Exhaust Gases of Natural Gas Fired Boilers, Biosystems Engineering 81(3), 323-332. 
Published: R. Andrews and J.M. Pearce, "Environmental and Economic Assessment of a Greenhouse Waste Heat Exchange”, Journal of Cleaner Production 19, pp. 1446-1454 (2011). http://dx.doi.org/10.1016/j.jclepro.2011.04.016

Chau J., Sowlati T., Sokhansanj, S., Preto, F., Melin, S., Bi, X., 2009. Techno-economic analysis of wood biomass boilers for the greenhouse industry. Applied Energy 86(3), 364-371.

Chertow, M.R. 2000. Industrial symbiosis: literature and taxonomy. Annual Review of Energy and the Environment 25, 313-337.

Desrochers, P. 2004. Industrial symbiosis: the case for market coordination. Journal of Cleaner Production 12(8), 1099-1110.

Doyle, W. and Pearce, J.M. 2009. Utilization of Virtual Globes for Open Source Industrial Symbiosis, Open Environmental Sciences 3, pp. 88-96.

Energy Information Association. 2009. Annual Energy Outlook 2010. EIA.

Garzoli, K. and Blackwell, J. 1987. An analysis of the nocturnal heat loss from a double skin plastic greenhouse. Journal of Agricultural Engineering Research 36(2), 75-86.

Government of Alberta: Energy. Alberta Gas Reference Price History. Accessed at: http://www.energy.alberta.ca/NaturalGas/1322.asp, [June 17, 2010]

Heeres, R., Vermeulen, W. and de Walle, F., 2004. Eco-industrial park initiatives in the USA and the Netherlands: first lessons. Journal of Cleaner Production 12, 985-995.

Helgeson, D., Petry, T., and Erlandson, G. 1986. An Economic Analysis of Operating a Simulated Two-Acre Greenhouse Utilizing Waste-Water Heat. North Central Journal of Agricultural Economics 8(1), 123-134.

Hnat, J.G, Coles, W.F, 1985. A Feasibility Assessment of Cogeneration from a Regenerative Glass Furnace, Industry Applications, IEEE Transactions On. IA-21, 1064-1069.

IAC. 2007. Industrial Assessment Centers Database. IAC Accessed at: http://www1.eere.energy.gov/industry/bestpractices/iacs.html, [June 10,2010]

Incorperated Energetics, 2004. Energy Loss Reduction and Recovery in Industrial Energy Systems. U.S. DOE.

Intergovernmental Panel on Climate Change (IPCC). 2007. IPCC Fourth Assessment Report: Climate Change 2007: Working group III: Mitigation of Climate Change.

Intergovernmental Panel on Climate Change (IPCC), 2008. Climate Change 2007: Synthesis Report. Cambridge University Press, Cambridge, United Kingdom.

Jacobsen, N., 2006. Industrial symbiosis in Kalundborg, Denmark: A quantitative assessment of economic and environmental aspects. Journal of Industrial Ecology 10(1-2), 239-255.

Jones, J., 1999. Tomato plant culture. Florida, CRC Press.

Kenny, R., Law, C., and Pearce, J.M. 2010. Towards Real Energy Economics: Energy Policy Driven by Life-Cycle Carbon Emission. Energy Policy 38, 1969-1978.

Kreith, F. and Goswami, D. Y. 2007. Handbook of Energy Efficiency and Renewable Energy. CRC Press.

Kobayashi H., Wu K., Switzer H. Martinez S. and Giudici R. 2005. $\mathrm{CO}_{2}$ reduction from glass melting furnaces by oxy-fuel firing combined with batch/cullet preheating. XX A.T.I.V. Conference Parma, Italy September 14-16. 
Published: R. Andrews and J.M. Pearce, "Environmental and Economic Assessment of a Greenhouse Waste Heat Exchange”, Journal of Cleaner Production 19, pp. 1446-1454 (2011). http://dx.doi.org/10.1016/j.jclepro.2011.04.016

Khinkis, M.Ya, Levitin, S.V., Gol’denberg, L.G. , Polyak, V.Ya., Zingman, L.I. 1968. Using waste gas heat from a glass furnace in a waste heat boiler. Glass and Ceramics, 25(1), 21-25.

Lovins, A., 1996. Negawatts: Twelve transitions, eight improvements, and one distraction. Energy Policy 24 (4), 331-344.

Maare, O., 1992. Economical Heat Supply of Greenhouses Experiences from Denmark. Acta Hort. (ISHS) 312, 37-44

Mirata, M., 2004. Experiences from early stages of a national industrial symbiosis programme in the UK: determinants and coordination challenges. Journal of Cleaner Production 12(8), 967-983.

Manning, T.O. and Mears, D.R. 1981. Computer-aided design of a greenhouse waste heat utilization system, Energy in Agriculture 1, 5-20 .

Nederhoff, E. and Houter, B., 2008. Greenhouse growers worldwide face despairingly high energy costs. Grower 63(8), 1-3.

Nilsen, S., Hovland, K., Dons, C., Sletten, S.P. 1983. Effect of $\mathrm{CO}_{2}$ enrichment on photosynthesis, growth and yield of tomato. Scientia Horticulturae 20(1), 1-14.

Nosrat, A.H., Jeswiet, J. and Pearce, J.M. 2009. Cleaner Production via Industrial Symbiosis in Glass and Large-Scale Solar Photovoltaic Manufacturing, Science and Technology for Humanity (TICSTH), 2009 IEEE Toronto International Conference, 967-970.

Nycz, J.A., Sturgill, D.T., 1980. A Waste Heat Recovery Boiler on a Glass-Melting Furnace. Proceedings of the $40^{\text {th }}$ Conference on Glass Problems 1(1/2) Chapter 3, 25-36.

OEE, 2006. The State of Energy Efficiency in Canada. Office of Energy Efficiency Report.

OIT, 2002. Best Practices case study: Anchor Glass Container Cooperation Plant-Wide Energy Assessment saves Electricity and Expenditures. U.S. D.O.E.

Olszewski, M. 1978. Use Of Waste Heat From Nuclear Power Plants. DOE Environmental Control Symposium Washington, DC November 14-16.

Olszewski, M. Hilenbrand, S.J. Reed, S.A. 1976. Waste heat vs conventional systems for greenhouse environmental control: An economic assessment.

Pearce, J.M., Johnson, S.J. and Gabriel B. Grant, G.B. 2007. 3D-Mapping Optimization of Embodied Energy of Transportation, Resources, Conservation and Recycling, 51, 435-453.

Pearce, J, 2008. Industrial Symbiosis for Very Large Scale Photovoltaic Manufacturing. Renewable Energy 33, 1101-1108.

Pellegrino, J., Sousa, L., Levine, E. 2002. Energy And Environtmental Profile of the U.S Glass Industry. Office of Industrial Technologies, Final report.

Queen's University. 2009. Live Building Data: Solar Irradiance. Queen's Live Building, Accessed at:http://livebuilding.queensu.ca/ [December 10,2009]

Reay, D.A., 1979. Industrial energy conservation:A Handbook for Engineers and Managers, $2^{\text {nd }}$ edition. Pergamon of Canada.

Richards, B.E., 1980. Chapter 6. Waste-Heat Boilers for Flat Glass Furnaces. Proceedings of the 40th Conference on Glass Problems: Ceramic Engineering and Science Proceedings 1(1/2), 50-58.

SaskPower. Shand Greenhouse . Accesed at: http://www.saskpower.com/shandgreenhouse/, [January. 
Published: R. Andrews and J.M. Pearce, "Environmental and Economic Assessment of a Greenhouse Waste Heat

Exchange”, Journal of Cleaner Production 19, pp. 1446-1454 (2011). http://dx.doi.org/10.1016/j.jclepro.2011.04.016

\section{$\underline{2,2010]}$}

Sims, R.E.H., 2004. Renewable energy: a response to climate change. Solar Energy 76, 9-17.

Soave Enterprises. 2009. Other Holdings - Diversified Holdings | Soave Enterprises . Published at: http://www.soave.com/core/diversified great.php,

Statistics Canada. 2008, Greenhouse, Sod and Nursery Industries. Statistics Canada, Catalogue no. 22-202-XWE.

Stern, N.H., Treasury, G.B., 2007. In: The Economics of Climate Change. Cambridge University Press, Cambridge, UK.

Thumann, A., 1977. Plant Engineers and Managers Guide to Energy Conservation. Van Nostrand Reinhold Company, New York.

Tiwari, G. 2003. Greenhouse technology for controlled environment. Alpha Science Int'l Ltd. Pangbourne, UK.

USDoE, 2009. Building Technologies Program: Energy Plus Simulation Software. Database.

US EPA, 1995 Compilation of Air Pollutant Emission Factors, Volume 1: Stationary Point and Area Sources. AP42, Fifth Edition Section 1.4.

Weseen, S. 2001.The Economics of Waste Heat Utilization in Greenhouses. CSALE Occasional Paper \#12.

Worrell, E., Galitsky, C., Masanet, E., Graus, W., 2008. Energy Efficiency Improvement and Cost Saving Opportunities for the Glass Industry. Berkeley National Laboratory.

World Bank Group, 1998. Glass Manufacturing. Pollution Prevention and Abatement Handbook, Wulfinghoff, D. R. 1999. Energy Efficiency Manual. Energy Institute Press: Wheaton, Maryland.

Zhang Y., Mahrer, Y. and Margolin, M. 1997. Predicting the microclimate inside a greenhouse: an application of a one-dimensional numerical model in an unheated greenhouse. Agricultural and Forest Meteorology 86(3-4), 291-297.

\section{Authors Bio:}

Rob Andrews is a M.Sc Candidate in the Applied Sustainability group at Queen's University. He received a B. SC. in Mechanical Engineering with first class honours from the same institution. His research focus is on photovoltaic system design and environmentally responsible manufacturing.

Joshua M. Pearce is an assistant professor of Mechanical and Materials Engineering at Queen's University, Ontario. His research includes applied sustainability, solar photovoltaic technology, energy policy, and engineering service learning. 
Published: R. Andrews and J.M. Pearce, "Environmental and Economic Assessment of a Greenhouse Waste Heat

Exchange”, Journal of Cleaner Production 19, pp. 1446-1454 (2011). http://dx.doi.org/10.1016/j.jclepro.2011.04.016

\section{Figures}

Figure 1:

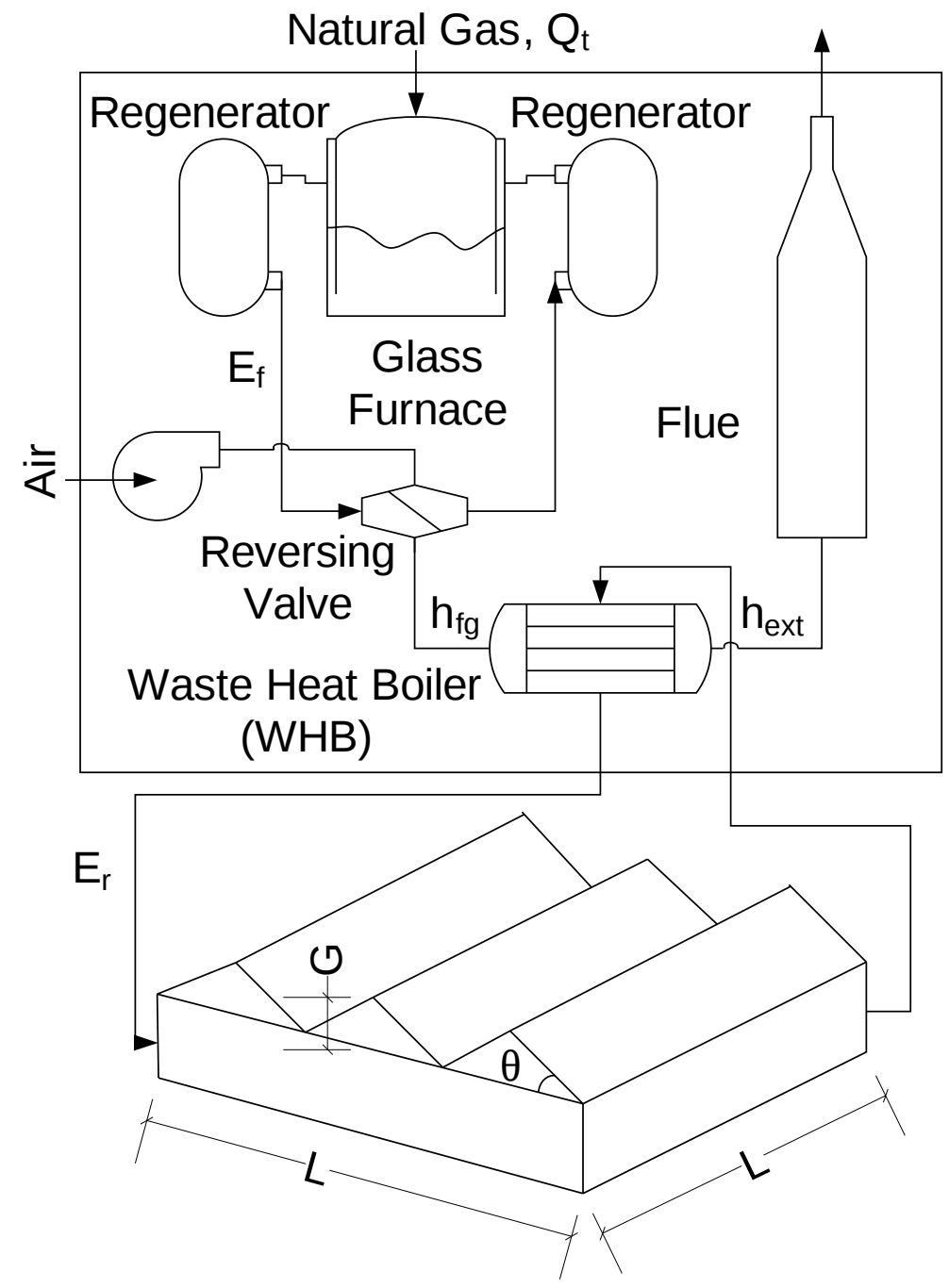

\section{Gutter Connected Greenhouse}

Figure 2

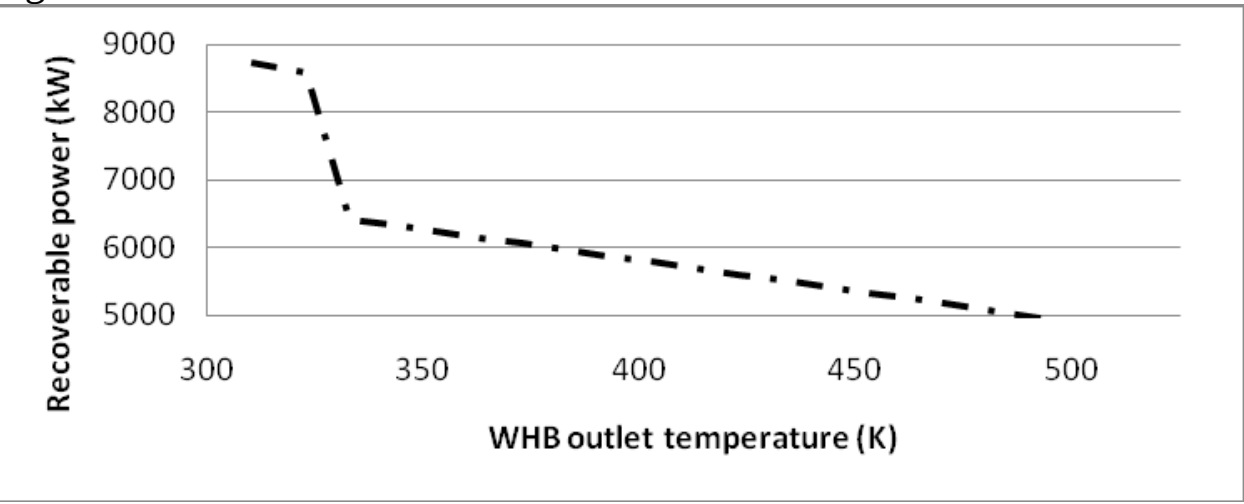


Published: R. Andrews and J.M. Pearce, "Environmental and Economic Assessment of a Greenhouse Waste Heat Exchange”, Journal of Cleaner Production 19, pp. 1446-1454 (2011). http://dx.doi.org/10.1016/j.jclepro.2011.04.016

Figure 3.

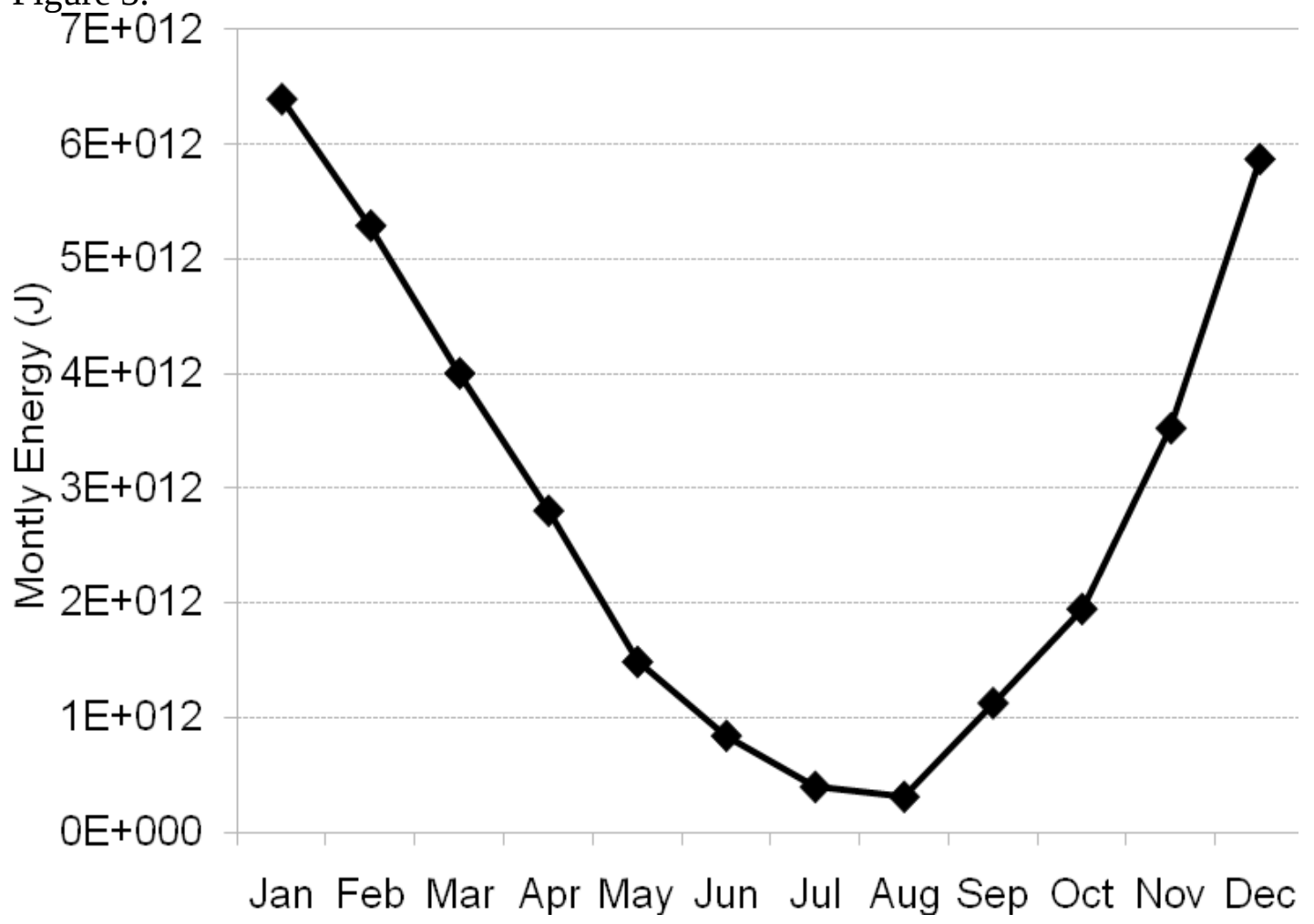

Figure 4

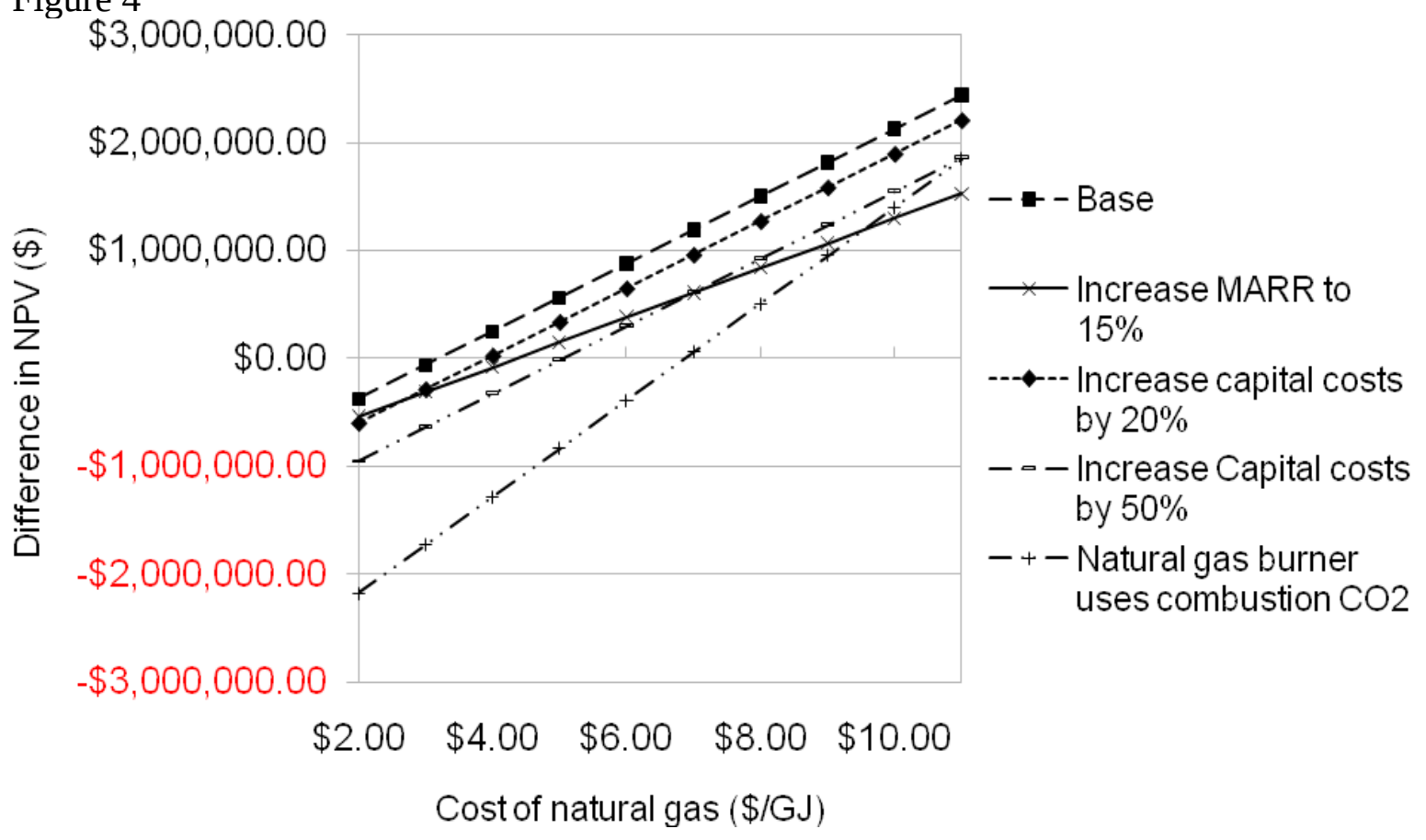

